\section{$\checkmark$ Research Square}

\title{
Public assistance program and depressive symptoms of the recipient: A cross-sectional Japan Gerontological Evaluation Study
}

Shiho Kino ( $\square$ shkino@hsph.harvard.edu )

Harvard University T H Chan School of Public Health https://orcid.org/0000-0002-9349-4980

Daisuke Nishioka

Osaka Medical College: Osaka Ika Daigaku

Keiko Ueno

University of Tokyo: Tokyo Daigaku

Maho Haseda

University of Tokyo: Tokyo Daigaku

Naoki Kondo

Kyoto University: Kyoto Daigaku

Research

Keywords: public assistance, depression, Japan, aged, social welfare

Posted Date: April 9th, 2021

DOl: https://doi.org/10.21203/rs.3.rs-403421/v1

License: (9) This work is licensed under a Creative Commons Attribution 4.0 International License.

Read Full License

Version of Record: A version of this preprint was published at BMC Geriatrics on March 3rd, 2022. See the published version at https://doi.org/10.1186/s12877-022-02868-0. 


\section{Abstract \\ Background}

Health inequality between public assistance recipients and non-recipients has been reported. However, it is not clear whether this is due to the participants' income inequality or because of other socioeconomic and psychosocial factors. We aimed to examine whether older recipients of public assistance were more likely to have depressive symptoms compared to non-recipients.

\section{Methods}

Data were obtained from the Japan Gerontological Evaluation Study, a 2016 community-based study of older adults. Poisson regression analyses with a robust error variance using fixed effects were conducted to examine the relationship between receiving public assistance and depressive symptoms controlling for sociodemographic factors. Depressive symptoms were assessed by the Geriatric Depression Scale 15.

\section{Results}

We found that the recipients of public assistance were 1.57 times $(95 \% \mathrm{Cl}: 1.47,1.67)$ more likely to have depressive symptoms compared to non-recipients. When additionally adjusting for indicators of social participation, this relationship was slightly attenuated; however, the recipients still had worse mental health (Incidence rate ratio: $1.33 ; 95 \% \mathrm{Cl}: 1.25,1.42$ ).

\section{Conclusions}

Even after controlling for sociodemographic factors, older recipients of public assistance were more likely to have depressive symptoms than non-recipients. However, social participation could slightly attenuate the negative relationship between receiving public assistance and depressive symptoms. Therefore, the public assistance program needs to consider inclusion of other healthcare supports in addition to financial support.

\section{Introduction}

Health inequality is one of the major challenges in public health (1). Targeting specific populations with socioeconomic difficulties has been considered as one of the methods to address health inequality (2). The Public Assistance program works as a safety net to ensure the minimum standard of living as well as to promote independence for all citizens living in poverty. Given that the COVID-19 pandemic has led to an increase in the number of people living in poverty, the importance of this program has increased. 
In Japan, eligibility for receiving public assistance is judged by municipal welfare offices, using information on personal assets, ability to work, relatives' financial support, and use of other welfare services. In September 2020, 1.63\% of Japanese residences had received public assistance (3). Although the evaluation of the income provided by the recipient varies depending on the household conditions (e.g., the living area, the number of people in the household, and other sources of income among other conditions), this program provides assistance covering most of the necessities, such as livelihood assistance, education assistance, housing assistance, medical assistance, long-term care assistance, maternity assistance, occupational assistance, and funeral assistance. Thus, one of the specific features of this program is that the recipients are financially protected in addition to receiving free access to healthcare, while non-recipients with the same income need to pay for these necessities. On the other hand, recipients of public assistance might be socially isolated and/or exposed to social stigma (4-6). Since these factors are strongly related to mental health(7), social participation might play an important role in influencing recipients' mental health.

A review of 32 papers summarized that poverty can be associated with mental illness (8). Another systematic review reported that recipients of public assistance had worse mental health than nonrecipients in high-income countries (9). On the other hand, an empirical study has reported that housing assistance was associated with improved health and psychological well-being (10).

The Japanese government reported that recipients of public assistance were more likely to have a risk of mental health problems than non-recipients (11). They found that the prevalence of mental health problems was $16.4 \%$ among public assistance recipients, while prevalence among non-recipients was $2.5 \%$ (11). In addition, a demographic survey showed that public assistance recipients had a higher risk of carrying out deliberate self-harm behaviors compared to non-recipients (12). These reports, however, did not consider influence of possible confounders (such as household income and comorbidity), and demographic factors which are well-known health risk factors (such as age, gender, marital status, and education). Therefore, it is not clear whether this difference in mental health is due to the participants' income levels, or because of other socioeconomic and psychosocial factors associated with being a recipient of public assistance program (i.e., social isolation and social stigma).

Furthermore, a review study reports that few studies have focused on health of older public assistance recipients (13). In Japan, the majority of public assistance recipients are older people (55.5\%) (3), and medical assistance occupies the largest portion of the public assistance budget (48.6\%) (14). Furthermore, medical expenditure is significantly higher among the recipients of public assistance compared to the patients using universal public health insurance (15), and the recipients of public assistance have a higher risk of frequent outpatient attendance (16). These studies indicate that other negative factors might be contributing to public assistance recipient's unhealthy behaviors or health conditions. Therefore, for sustainable public health programs, it would be unavoidable to consider role of additional factors in effecting health of older recipients of public assistance. In this study, we aimed to examine the relationship between receiving public assistance and depressive symptoms among older Japanese adults. 


\section{Methods}

\section{Study population}

We used cross-sectional data from a nationwide cohort study in Japan conducted in 2016, called the Japan Gerontological Evaluation Study (JAGES). JAGES aimed to examine social determinants of healthy aging among older people by mailing self-reporting questionnaires to approximately 280,000 community-dwelling individuals aged 65 years and older in 39 municipalities. The participants were selected by municipal unit: Randomly selected individuals were included from 22 large municipalities where the population aged 65 years and older was over 5000 people, while all older individuals were included from 17 small municipalities where it was less than 5000 people. The total number of participants was 196,438; the response rate was $70.2 \%$. We excluded individuals who had missing values in the variables used in this study.

\section{Public assistance status}

The participants were asked whether they received public assistance when they answered the questionnaire. The question had three response options: "not receiving public assistance," "receiving public assistance," and "applying for public assistance." Individuals who answered "applying for public assistance" to this question ( $0.03 \%$ of the responses) were excluded from the sample.

\section{Outcome variables}

We used depressive symptoms as an outcome. Depressive symptoms were measured using the Japanese short version of the Geriatric Depression Scale (GDS) with 15 binary questions $(17,18)$. The questions include (1) Are you basically satisfied with your life? (reverse coded) (2) Have you dropped many of your activities and interests? (3) Do you feel that your life is empty? (4) Do you often get bored? (5) Are you in good spirits most of the time? (reverse coded) (6) Are you afraid that something bad is going to happen to you? (7) Do you feel happy most of the time? (reverse coded) (8) Do you often feel helpless? (9) Do you prefer to stay at home, rather than going out and doing new things? (10) Do you feel you have more problems with memory than most? (11) Do you think it is wonderful to be alive now? (reverse coded) (12) Do you feel pretty worthless the way you are now? (13) Do you feel full of energy? (reverse coded) (14) Do you feel that your situation is hopeless? (15) Do you think that most people are better off than you are? Then, the overall summed score (range: $0-15)$ was dichotomized, and individuals with a score of $\geq 5$ were considered to have depressive symptoms. This cutoff point was validated to screen major depressive symptoms with area under the ROC curve of 0.94 (sensitivity of $92 \%$ and specificity of 87\%) against the Structured Clinical Interview for the Diagnostic and Statistical Manual of Mental Disorders, Third Edition, Revised, as the gold standard (19).

\section{Explanatory variables}

We considered sociodemographic characteristics including age (continuous), gender (male vs. female), marital status (non-married [single, widowed, or divorced] vs. married), and education (9 years or less vs. 
more than 9 years). Additionally, we controlled for household income (including subsidies based on public assistance and pension), number of household members, and comorbidity. Comorbidity was assessed by counting the number of the following 16 diagnosed diseases (range: $0-16$ ): hypertension, stroke (e.g., brain hemorrhage), heart disease, diabetes, hyperlipidemia, respiratory disease (e.g., pneumonia, bronchitis), gastrointestinal, liver or gallbladder disease, kidney or prostate gland disease, musculoskeletal disease (e.g., osteoporosis, arthrosis), traumatic injury (e.g., fall, fracture), cancer, blood or immune system disease, dementia (e.g., Alzheimer's disease), Parkinson's disease, eye disease, and ear disease.

One of the issues faced by recipients of public assistance is social isolation (4). Hence, social participation was included as a proxy for social isolation. Informal socializing/social participation was assessed by the following four items $(20,21)$ : (1) "How often do you see your friends?" (2) "How many friends/acquaintances have you seen over the past month? Count the same person as one, no matter how many times you have seen him/her." (3) "How often do you attend activities for sports club?" (4) "How often do you attend activities for hobby clubs?" Ratings for items one, three and four ranged from 1 (rarely) to 6 (almost every day). Ratings for item two ranged from 1 (none) to 5 (10 or more). Responses to each item were standardized, resulting in a mean of zero and a standard deviation of one. Higher scores indicate greater social participation.

\section{Statistical analysis}

All analyses were performed using Stata MP16 (22). Descriptive statistics were used to compare the scores of recipients and non-recipients of public assistance.

We performed a series of Poisson regression analyses with a robust error variance using fixed effects to consider geographical variations. First, we adjusted only for age and gender (Model 1). In Model 2, education and marital status were further adjusted for. We additionally controlled for household income, number of household members, and comorbidity (Model 3). In the fully adjusted model, the four indicators of social participation were also included (Model 4). From each model, incidence rate ratios (IRR) were presented. The significance level for all statistical analyses was kept at $p<.05$.

As a sensitivity analysis, we employed the propensity score matching method to match the conditions between recipients of public assistance and non-recipients. To calculate the propensity scores, we selected the three variables which are evaluated when considering applications for public assistance in Japan: household income, number of household members, and comorbidity. We used one-to-one caliper (0.2) matching with no replacement, using Stata command "teffect psmatch." In order to confirm the matching balance between the two groups, we checked that the standardized differences were lower than 0.1 after matching. Then, we performed a series of Poisson regression analyses with a robust error variance using fixed effects.

\section{Results}


Table 1 shows the characteristics of the study participants. Out of 93,280 participants who answered all the variables used for the analyses, 1,093 (1.17\%) received public assistance. More than half of the recipients had depressive symptoms, while $21 \%$ of non-recipients had depressive symptoms. The group of recipients included more male, less educated, and single people compared to the group of nonrecipients. In addition, household income was more than twice higher among non-recipients. Number of household members was higher (2.62 vs. 1.85), while comorbidity was lower (1.45 vs. 1.65) among nonrecipients compared to recipients. In addition, non-recipients had a higher level of social participation. 
Table 1

Demographic characteristics of analytic samples

\begin{tabular}{|c|c|c|}
\hline & $\begin{array}{l}\text { Recipients of public } \\
\text { assistance }\end{array}$ & $\begin{array}{l}\text { Non-recipients of public } \\
\text { assistance }\end{array}$ \\
\hline & $(n=1,093)$ & $(\mathrm{n}=92,187)$ \\
\hline Depressive symptoms (GDS > = 5) & $50.14 \%(n=548)$ & $20.68 \%(n=19,064)$ \\
\hline Age (mean) & $72.91(\mathrm{SD}=5.84)$ & $73.11(\mathrm{SD}=5.97)$ \\
\hline \multicolumn{3}{|l|}{ Sex } \\
\hline Male & $56.82 \%(n=621)$ & $52.16 \%(n=48081)$ \\
\hline Female & $42.18 \%(n=472)$ & $47.84 \%(n=44,106)$ \\
\hline \multicolumn{3}{|l|}{ Education } \\
\hline$\leqq 9$ years & $42.36 \%(n=463)$ & $25.90 \%(n=23,877)$ \\
\hline$>9$ years & $57.64 \%(n=630)$ & $74.10 \%(n=68,310)$ \\
\hline \multicolumn{3}{|l|}{ Marital status } \\
\hline Single & $61.94 \%(n=677)$ & $22.48 \%(n=20,728)$ \\
\hline Married & $38.06 \%(n=416)$ & $77.52 \%(n=71,459)$ \\
\hline $\begin{array}{l}\text { Household income (mean; } \\
\text { JPY10000) }\end{array}$ & $188.33(\mathrm{SD}=205.13)$ & $399.88(S D=276.01)$ \\
\hline Household number (mean) & $1.85(\mathrm{SD}=1.25)$ & $2.62(S D=1.35)$ \\
\hline Comorbidity (mean) & $1.65(\mathrm{SD}=1.35)$ & $1.45(\mathrm{SD}=1.25)$ \\
\hline Meeting friends (mean) & $3.11(S D=1.65)$ & $3.63(S D=1.58)$ \\
\hline Number of friends (mean) & $2.72(S D=1.33)$ & $3.50(S D=1.36)$ \\
\hline $\begin{array}{l}\text { Participation in sports clubs } \\
\text { (mean) }\end{array}$ & $1.45(\mathrm{SD}=1.20)$ & $2.14(\mathrm{SD}=1.71)$ \\
\hline $\begin{array}{l}\text { Participation in hobby clubs } \\
\text { (mean) }\end{array}$ & $1.55(\mathrm{SD}=1.21)$ & $2.23(\mathrm{SE}=1.60)$ \\
\hline SD: standard deviation & & \\
\hline
\end{tabular}

Table 2 shows the results of the Poisson regression with a robust error variance using fixed effects to examine the relationship between depressive symptoms and receiving public assistance. The recipients of public assistance were about twice as likely to have depressive symptoms in the model adjusted for age and gender (Model 1) (IRR: 2.38; 95\% Confidence Interval [Cl]: 2.24, 2.53) and the model further adjusted for marital status and education (Model 2) (IRR: 1.91; 95\% Cl: 1.79, 2.03). Furthermore, in the 
model additionally adjusted for household income, number of household members, and comorbidity, the IRR slightly dropped to $1.57(95 \% \mathrm{Cl}: 1.47,1.67)$ (Model 3$)$. In this fully adjusted model (Model 4), the recipients were 1.33 times $(95 \% \mathrm{Cl}: 1.25,1.42)$ more likely to have depressive symptoms. Those meeting friends frequently, meeting a greater number of friends, participating in sports clubs, and participating in hobby clubs were $0.88(95 \% \mathrm{Cl}: 0.86,0.89), 0.81(95 \% \mathrm{Cl}: 0.80,0.83), 0.90(95 \% \mathrm{Cl}: 0.88,0.92)$, and 0.89 times $(95 \% \mathrm{Cl}: 0.87,0.90)$ less likely to have depressive symptoms.

Table 2

The relationship between depressive symptoms and public assistance from Poisson regression analyses with a robust error variance using fixed effects

\begin{tabular}{|c|c|c|c|c|c|c|c|c|}
\hline & \multicolumn{2}{|c|}{ Model 1} & \multicolumn{2}{|c|}{ Model 2} & \multicolumn{2}{|c|}{ Model 3} & \multicolumn{2}{|c|}{ Model 4} \\
\hline & IRR & $95 \% \mathrm{Cl}$ & IRR & $95 \% \mathrm{Cl}$ & IRR & $95 \% \mathrm{Cl}$ & IRR & $95 \% \mathrm{Cl}$ \\
\hline Public assistance (ref: no) & 2.38 & $\begin{array}{l}(2.24- \\
2.53)\end{array}$ & 1.91 & $\begin{array}{l}(1.79- \\
2.03)\end{array}$ & 1.57 & $\begin{array}{l}(1.47- \\
1.67)\end{array}$ & 1.33 & $\begin{array}{l}(1.25- \\
1.42)\end{array}$ \\
\hline Age (continuous) & 1.02 & $\begin{array}{l}(1.02- \\
1.02)\end{array}$ & 1.01 & $\begin{array}{l}(1.01- \\
1.01)\end{array}$ & 1.01 & $\begin{array}{l}(0.99- \\
1.01)\end{array}$ & 0.99 & $\begin{array}{l}(0.99- \\
1.01)\end{array}$ \\
\hline Sex (ref. male) & 0.97 & $\begin{array}{l}(0.95- \\
0.99)\end{array}$ & 0.87 & $\begin{array}{l}(0.84- \\
0.89)\end{array}$ & 0.88 & $\begin{array}{l}(0.86- \\
0.90)\end{array}$ & 1.02 & $\begin{array}{l}(0.99- \\
1.05)\end{array}$ \\
\hline $\begin{array}{l}\text { Education > 9years (ref: } \\
\leqq 9 \text { years) }\end{array}$ & & & 0.73 & $\begin{array}{l}(0.71- \\
0.75)\end{array}$ & 0.81 & $\begin{array}{l}(0.78- \\
0.83)\end{array}$ & 0.87 & $\begin{array}{l}(0.85- \\
0.90)\end{array}$ \\
\hline Marital status (ref. single) & & & 0.69 & $\begin{array}{l}(0.67- \\
0.71)\end{array}$ & 0.74 & $\begin{array}{l}(0.72- \\
0.76)\end{array}$ & 0.76 & $\begin{array}{l}(0.74- \\
0.78)\end{array}$ \\
\hline $\begin{array}{l}\text { Household income } \\
\text { (continuous) }\end{array}$ & & & & & 0.99 & $\begin{array}{l}(0.99- \\
0.99)\end{array}$ & 0.99 & $\begin{array}{l}(0.99- \\
0.99)\end{array}$ \\
\hline $\begin{array}{l}\text { Number of household } \\
\text { members (continuous) }\end{array}$ & & & & & 1.04 & $\begin{array}{l}(1.03- \\
1.05)\end{array}$ & 1.02 & $\begin{array}{l}(1.01- \\
1.03)\end{array}$ \\
\hline Comorbidity (continuous) & & & & & 1.21 & $\begin{array}{l}(1.20- \\
1.22)\end{array}$ & 1.19 & $\begin{array}{l}(1.18- \\
1.20)\end{array}$ \\
\hline Meeting friends (z score) & & & & & & & 0.88 & $\begin{array}{l}(0.86- \\
0.89)\end{array}$ \\
\hline Number of friends (z score) & & & & & & & 0.81 & $\begin{array}{l}(0.80- \\
0.83)\end{array}$ \\
\hline $\begin{array}{l}\text { Participation in sports clubs } \\
\text { (z score) }\end{array}$ & & & & & & & 0.90 & $\begin{array}{l}(0.88- \\
0.92)\end{array}$ \\
\hline $\begin{array}{l}\text { Participation in hobby clubs } \\
\text { (z score) }\end{array}$ & & & & & & & 0.89 & $\begin{array}{l}(0.87- \\
0.90)\end{array}$ \\
\hline IRR: Incidence rate ratio & & & & & & & & \\
\hline
\end{tabular}


As a sensitivity analysis, we conducted propensity score matching and then analyzed the relationship between receiving public assistance and depressive symptoms. We obtained the same findings as the main findings.

\section{Discussion}

This study examined the relationship between receiving public assistance and depressive symptoms among older Japanese people. We found that public assistance recipients were more likely to have depressive symptoms than those without public assistance. Furthermore, we found that this negative relationship between public assistance and depressive symptoms could be attenuated by social participation.

While public assistance financially protects people, these findings suggest that recipients of public assistance would face other burdens. First, the recipients might have faced social stigma, which could be one of the reasons of depressive symptoms. The support for them is financed through the nation's taxes; therefore, some recipients might feel that they live without working (internal stigma) (5) and some nonrecipients might feel prejudice against receiving public assistance (external stigma) (6). Social stigma results in mental health issues among some recipients. Furthermore, this stigma-based mental stress might lead to unhealthy behaviors causing further health problems (23). Second, they might have already had health issues when they started receiving public assistance. Receiving public assistance is partially assessed by the ability to work. Some people might not be able to work due to mental health problems or other health problems in addition to mental illness. In fact, $25.1 \%$ of recipients receive public assistance due to injury or illness (24). Third, the recipients might be isolated from society, which might have a negative impact on their mental health. Reviews have reported the well-established evidence that social isolation is related to worse health $(7,25,26)$. In addition, Fukawa suggested that social participation is essential for recipients to remove social isolation and improve independence (4).

Our findings suggest some policy implications. First, we suggest reinforcing skill training for caseworkers to prevent inappropriate communication from contributing to social stigma and social isolation. Although caseworkers have finished the designated course of social work and are certified by the government, they currently have a heavy workload that may result in difficulties in providing sensitive support for recipients. Second, the regular visits made by the caseworkers to the recipients' residence can be further used; caseworkers can connect the recipients with other health professionals, such as public health nurses, psychiatric social workers, or clinical psychologists if they notice issues related to their mental health during the visits. This is because the primary focus of caseworkers is on providing support for employment, not on monitoring health concerns. Third, from July 2020, the Social Welfare Act added the reinforcement of community support with financial support for public assistance recipients (27). This act aims to support people who suffer from poverty, providing comprehensive, individual, early, continuous, decentralized, and creative support, in order to secure independence and dignity, and create a supportive community. In addition, from January 2021, health management support for recipients of public assistance by welfare workers is mandatory by law for welfare offices of municipalities that provide 
public assistance $(28,29)$. Taking advantage of these initiatives, we suggest strengthening partnerships between medical and social care providers and informal and formal community programs that can alleviate the problems of isolation and stigma (e.g., through social prescribing activities) (30).

This study would be the first study to present depressive symptoms among public assistance recipients in older Japanese population, while there are some limitations. This is a cross-sectional study. Therefore, we could not establish the temporality, which may lead to reverse causation. For example, depressive symptoms might be a reason for reluctant social participation. In addition, we could not consider personal assets in the analysis, which is an important factor for receiving public assistance. In particular, if non-recipients have assets other than income, our findings might be underestimated. However, it is difficult to compare possession of assets and spending on necessities, including medical costs. This suggests that future studies should consider personal assets. Lastly, even though the number of comorbidities between the recipients and non-recipients were matched, the severity of health problems could not be considered.

\section{Conclusions}

In conclusion, we found that older recipients of public assistance in Japan were more likely to have depressive symptoms than non-recipients. However, social participation could slightly attenuate the negative relationship between receiving public assistance and depressive symptoms. Our findings suggest that the public assistance program would need to consider inclusion of mental health support and community support in addition to financial support. Future studies should explore the role of community and social characteristics that can potentially mitigate or strengthen the non-financial risk factors for mental health among public assistance recipients, such as social capital and social stigma.

\section{Abbreviations}

GDS: The Geriatric Depression Scale 15

IRR: Incidence rate ratio

JAGES: The Japan Gerontological Evaluation Study

SD: Standard deviation

\section{Declarations}

Ethics approval and consent to participate

The JAGES protocol was approved by the ethics committee on human subjects at Nihon Fukushi University (No. 13-14), Chiba University (No. 2493), and the National Center for Geriatrics and Gerontology (No. 992). 


\section{Consent for publication}

Not applicable.

\section{Availability of data and materials}

The datasets generated and/or analyzed during the current study are available in the Japan Gerontological Evaluation Study repository, https://www.jages.net/

\section{Competing interests}

Shiho Kino, Daisuke Nishioka, Keiko Ueno, Maho Haseda, and Naoki Kondo declare no competing interests associated with this manuscript.

\section{Funding}

This study was supported by Grant-in-Aid for JSPS Fellows (JP20J01910), JSPS KAKENHI Grant Number (JP15H01972), Health Labour Sciences Research Grant (H28-Choju-Ippan-002), Japan Agency for Medical Research and Development (AMED) (JP17dk0110017, JP18dk0110027, JP18ls0110002, JP18le0110009, JP20dk0110034, JP20dk0110037), Open Innovation Platform with Enterprises, Research Institute and Academia囚OPERA, JPMJOP1831囚from the Japan Science and Technology (JST), a grant from Innovative Research Program on Suicide Countermeasures (1-4) , a grant from Sasakawa Sports Foundation, a grant from Japan Health Promotion \& Fitness Foundation, a grant from Chiba Foundation for Health Promotion \& Disease Prevention, the 8020 Research Grant for fiscal 2019 from the 8020 Promotion Foundation (adopted number: 19-2-06), a grant from Niimi University (1915010), grants from Meiji Yasuda Life Foundation of Health and Welfare and the Research Funding for Longevity Sciences from National Center for Geriatrics and Gerontology (29-42, 30-22).

\section{Authors' contributions}

SK, DN, KU, MH, and NK conceptualized and designed the study. SK analyzed the data and prepared the manuscript. DN, KU, and $\mathrm{MH}$ reviewed the manuscript. NK finalized the manuscript. All authors read and approved the final manuscript.

Acknowledgements

We would like to thank Editage [http://www.editage.com] for editing and reviewing this manuscript.

\section{References}

1. Marmot M. Social determinants of health inequalities. The Lancet [Internet]. 2005 Mar 19 [cited 2018 Nov 28];365(9464):1099-104. Available from:

https://www.sciencedirect.com/science/article/pii/S0140673605711466 
2. Frohlich KL, Potvin L. Transcending the known in public health practice: The inequality paradox: The population approach and vulnerable populations [Internet]. Vol. 98, American Journal of Public Health. Am J Public Health; 2008 [cited 2021 Feb 12]. p. 216-21. Available from: https://pubmed.ncbi.nlm.nih.gov/18172133/

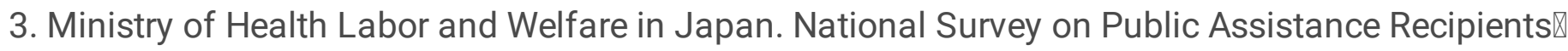
Report of investigation (in Japanese) [Internet]. 2020 [cited 2021 Jan 3]. Available from: https://www.mhlw.go.jp/toukei/list/74-16b.html

4. Fukawa H. The Public Assistance System and Social Exclusion. Japanese Journal of Family Sociology. 2007;18(2):37-46.

5. Takahashi M. Spatial Probit Analysis on Welfare Stigma: Evidence from Japan. 2017.

6. Kurita K. Survey of economic study for stigma of public assistance (in Japanese) [Internet]. 2017 [cited 2021 Feb 1]. Available from: https://catalog.lib.kyushu-u.ac.jp/opac_detail_md/? lang $=0$ \&amode $=$ MD100000\&bibid $=1812532$

7. Courtin E, Knapp M. Social isolation, loneliness and health in old age: a scoping review [Internet]. Vol. 25, Health and Social Care in the Community. Blackwell Publishing Ltd; 2017 [cited 2021 Feb 1]. p. 799-812. Available from: https://pubmed.ncbi.nlm.nih.gov/26712585/

8. Lepiéce B, Reynaert C, Jacques D, Zdanowicz N. Poverty and mental health: What should we know as mental health professionals? Psychiatr Danub [Internet]. 2015 [cited 2021 Feb 23];Suppl 1:592-6. Available from: https://pubmed.ncbi.nlm.nih.gov/26417741/

9. Shahidi F v., Ramraj C, Sod-Erdene O, Hildebrand V, Siddiqi A. The impact of social assistance programs on population health: A systematic review of research in high-income countries. BMC Public Health [Internet]. 2019 Jan 3 [cited 2021 Jan 7];19(1). Available from: https://pubmed.ncbi.nlm.nih.gov/30606263/

10. Fenelon A, Mayne P, Simon AE, Rossen LM, Helms V, Lloyd P, et al. Housing assistance programs and adult health in the United States [Internet]. Vol. 107, American Journal of Public Health. American Public Health Association Inc.; 2017 [cited 2021 Jan 3]. p. 571-8. Available from: https://pubmed.ncbi.nlm.nih.gov/28207335/

11. Ministry of Health Labor and Welfare in Japan. Number of suicides among public assistance recipients (in Japanese) [Internet]. 2010 [cited 2021 Jan 3]. Available from: https://www.mhlw.go.jp/shingi/2010/04/dl/s0419-5e.pdf

12. Nakanishi M, Endo K, Ando S. The basic act for suicide prevention: Effects on longitudinal trend in deliberate self-harm with reference to national suicide data for 1996-2014. International Journal of Environmental Research and Public Health [Internet]. 2017 Jan 21 [cited 2021 Jan 3];14(1). Available from: https://pubmed.ncbi.nlm.nih.gov/28117707/

13. Hara M, Kuroda K. Health support for recipients of livelihood protection: A review of the needs and consideration of a support system. Journal of Human Health Science. 2019;12:15-8.

14. Ministry of Health Labor and Welfare in Japan. Overview of public assistance program: Working group of development of verification method for public assitance evaluation (in Japanese) [Internet]. 
2019 [cited 2021 Jan 3]. Available from: https://www.mhlw.go.jp/content/12002000/000488808.pdf

15. Yuda M. The medical assistance system and inpatient health care provision: Empirical evidence from short-term hospitalizations in Japan. PLoS ONE [Internet]. 2018 Oct 1 [cited 2021 Jan 3];13(10). Available from: https://pubmed.ncbi.nlm.nih.gov/30286118/

16. Nishioka D, Saito J, Ueno K, Kondo N. Frequent outpatient attendance among people on the governmental welfare programme in Japan: Assessing both patient and supplier characteristics. BMJ Open [Internet]. 2020 Oct 19 [cited 2021 Jan 8];10(10). Available from: https://pubmed.ncbi.nlm.nih.gov/33077566/

17. Greenberg SA. The Geriatric Depression Scale (GDS) validation of a geriatric depression screening scale: A preliminary report [Internet]. 2019 [cited 2019 Oct 24]. Available from: http://www.stanford.edu/ yesavage/ACRC.htmlhttp://www.stanford.edu/ yesavage/GDS.html.

18. Sheikh JI, Yesavage JA. Geriatric depression scale (GDS) recent evidence and development of a shorter version. Clinical Gerontologist. 1986 Nov 18;5(1-2):165-73.

19. Lyness JM, Noel TK, Cox C, King DA, Conwell Y, Caine ED. Screening for depression in elderly primary care patients: A comparison of the Center for Epidemiologic Studies-Depression Scale and the Geriatric Depression Scale. Archives of Internal Medicine. 1997;157(4):449-54.

20. Hikichi H, Sawada Y, Tsuboya T, Aida J, Kondo K, Koyama S, et al. Residential relocation and change in social capital: A natural experiment from the 2011 Great East Japan Earthquake and Tsunami. Science Advances [Internet]. 2017 Jul 5 [cited 2021 Feb 8];3(7):1700426. Available from: /pmc/articles/PMC5529061/?report=abstract

21. Hikichi H, Tsuboya T, Aida J, Matsuyama Y, Kondo K, Subramanian S, et al. Social capital and cognitive decline in the aftermath of a natural disaster: a natural experiment from the 2011 Great East Japan Earthquake and Tsunami. Lancet Planet Health. 2017;1(3):e105-13.

22. StataCorp. Stata Statistical Software: Release 16. College Station. TX: StataCorp LLC; 2019.

23. Boyle MP, Fearon AN. Self-stigma and its associations with stress, physical health, and health care satisfaction in adults who stutter. Journal of Fluency Disorders [Internet]. 2018 Jun 1 [cited 2021 Feb 8];56:112-21. Available from: https://pubmed.ncbi.nlm.nih.gov/29111141/

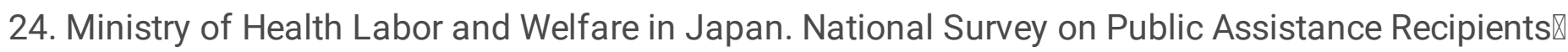
Report of investigation (in Japanese) [Internet]. Vol. 7. 2016 [cited 2021 Jan 3]. Available from: https://www.mhlw.go.jp/toukei/saikin/hw/hihogosya/m2017/dl/kakutei.pdf

25. Holt-Lunstad J, Smith TB, Layton JB. Social Relationships and Mortality Risk: A Meta-analytic Review. Brayne C, editor. PLoS Medicine [Internet]. 2010 Jul 27 [cited 2021 Feb 8];7(7):e1000316. Available from: https://dx.plos.org/10.1371/journal.pmed.1000316

26. Holt-Lunstad J, Smith TB, Baker M, Harris T, Stephenson D. Loneliness and Social Isolation as Risk Factors for Mortality: A Meta-Analytic Review. Perspectives on Psychological Science [Internet]. 2015 Mar 16 [cited 2021 Feb 8];10(2):227-37. Available from: https://pubmed.ncbi.nlm.nih.gov/25910392/ 
27. Ministry of Health Labor and Welfare. Municipality administrative manual of independence support system for people in need (in Japanese) [Internet]. 2020 [cited 2021 Feb 2]. Available from: https://www.mhlw.go.jp/content/000646672.pdf

28. Japan Gerontological Evaluation Study. Survey on health management support for recipients of public assistance (in Japanese) [Internet]. 2020 [cited 2021 Feb 1]. Available from: https://www.jages.net/?action=common_download_main\&upload_id=9506

29. Ministry of Health Labor and Welfare. Meeting document of Social Welfare and War Victims' Relief Bureau (in Japanese). 2019.

30. Roland M, Everington S, Marshall M. Social Prescribing - Transforming the Relationship between Physicians and Their Patients. New England Journal of Medicine [Internet]. 2020 Jul 9 [cited 2021 Feb 1];383(2):97-9. Available from: https://www.nejm.org/doi/10.1056/NEJMp1917060 